
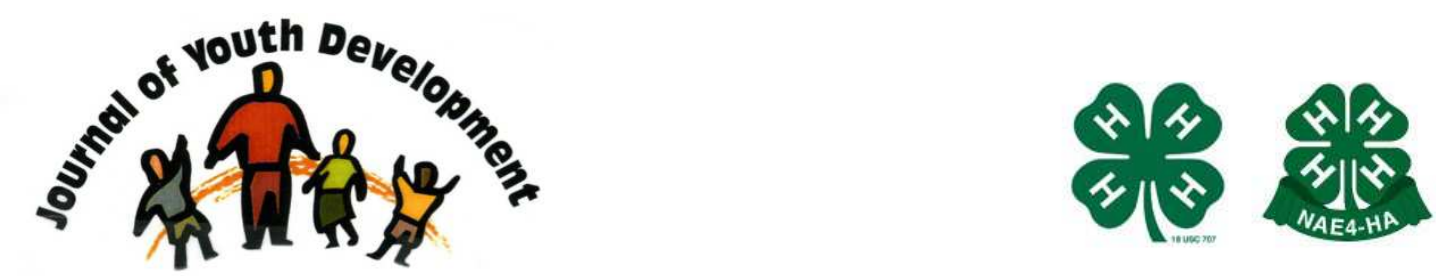

Bridging Research \& Practice

\title{
Organizational Support for Sexual Minority Adolescents: Effects of Level of Youth Involvement and Diversity Training
}

\author{
Christine R. Regan \\ Department of Family, Youth and Community Sciences \\ University of Florida \\ cregan@indigoconsulting.net \\ Marilyn Swisher \\ Department of Family, Youth and Community Sciences \\ University of Florida \\ meswisher@ifas.ufl.edu \\ Rosemary V. Barnett \\ Department of Family, Youth and Community Sciences \\ University of Florida \\ rbarnet@ufl.edu
}




\title{
JOURNAL OF YOUTH DEVELOPMENT \\ bridging research and practice
}

\section{Organization Support for Sexual Minority Adolescents: Effects of Level of Youth Involvement and Diversity Training}

\author{
Christine R. Regan, Marilyn Swisher and Rosemary V. Barnett \\ University of Florida
}

\begin{abstract}
A two-phase, cross-section and case study design examined the level of youth involvement in the decision-making processes of youth-serving organizations and the effects of diversity training on organizational support for LGBT (lesbian, gay, bisexual and transgendered) adolescents. Results indicate the organizations studied differed with respect to levels of youth involvement, but did not significantly differ with respect to the outcome variable. In-depth analysis to open-response questions indicated organizational support is extremely varied and organizations do support diversity, but not necessarily in regard to LGBT adolescents. The LGBT content within diversity training programs is also discussed. Finally, some religious ideas or beliefs seem to negatively affect the environment in youthserving organizations in regard to support for LGBT adolescents. Implications for further research, youth practitioners and organizations are discussed.
\end{abstract}

\section{Introduction}

\section{Adolescents of LGBT Parents}

The precise number of children in America presently being raised by gay, lesbian, or bisexual parents is unknown, however, it is estimated that two to eight million parents in the United States are LGBT (Casper, \& Schultz, 1999; HRW, 2001; Patterson, 1995b). Many studies indicate the numbers of children with same-sex parents in America are significant (Simmons, \& O'Connell, 2003). The 2000 U.S. Census reported there are approximately 600,000 same-sex couples, of which over $50 \%$ have at least one child. A 1995 National Health and Social Life Survey by E.O. Lauman found that up to eight million children in America have gay or lesbian parents (Committee on Psychosocial Aspects of Child and Family Health, 2002). Resistance to 
lesbian and gay rights continues to force many lesbian and gay people to remain silent about their sexual orientation and relationships and, therefore, may skew Census results.

Research has revealed that adolescents with gay or lesbian parents are ridiculed or treated poorly, even though their children may themselves be heterosexual (D'Augelli, \& Hershberger, 1993; HRW, 2001; Lassiter, et al., 2006). It is difficult to estimate accurately the number of LGBT youth and individuals who are negatively affected through social ties with this minority population, but the number is undoubtedly high.

\section{LGBT Adolescents}

Although the majority of youth are heterosexual, there are more than two million school-aged lesbian, gay, bisexual, and transgender youth, or sexual minority youth (Human Rights Watch, 2005; National Mental Health Association, 2005). This number does not include youth who are questioning their sexuality, unsure about it, or not yet open about their sexual orientation.

All adolescents experience the same physical, cognitive, psychological and social processes of development. One of the major psychological tasks of adolescence is to form self-identity and sexual identity. LGBT adolescents sometimes face challenges that heterosexual adolescents do not. This can occur because reaching sexual identity is often more confusing for LGBT youth because their identity may not fit with the typical gender conformity roles established by a homophobic society (Arnett, 2003; Herek, 1988). This can create stress and identity confusion that may permeate adolescence and transcend into emerging adulthood (Arnett, 2003). Many LGBT youth feel unsafe or uncomfortable engaging in affectionate behaviors, even though it is common during adolescence, for fear of rejection or being teased by peers (Cobb, 2004).

Research shows that adolescent sexual minority youth are at an increased risk for a number of problematic behaviors, including:

- Drug abuse (D'Augelli, et al., 2001; Grossman, \& Kerner, 1998)

- Homelessness (Kruks, 1991; National Runaway Switchboard, 2006)

- Low-self esteem (Grossman, \& Kerner, 1998; Unks, 1993)

- Victimization (Cato, \& Canetto, 2003; Cochran, \& Mays, 2001; Hetrick, \& Martin, 1987; Mufioz-Plaza, et al., 2002; Remafedi, G., 1987)

- Depression and suicidal ideation (Cato, et al., 2003; D'Augelli, et al., 2001; D'Augelli, et al., 2002; Garofalo, et al., 1999; Garofalo, et al., 1998; Hershberger, et al., 1995; McDaniel, et al., 2001; Rivers, 2000; Rotheram-Borus \& Fernandez, 1995).

\section{Inadequate Support}

Another important step in the development of LGBT sexual identity is immersion of these youth into social networks. Research has consistently indicated that social contacts with other LGBT adolescents help the individual come to terms with a self-definition of sexual orientation, as well as provide support to cope with the stigma and feelings of alienation and isolation from the heterosexual world (Cass, 1979, 1996; D’Augelli, 1996; Herdt, \& Boxer, 1993; Savin-Williams, 1995).

Adolescence is a difficult time for all people, but researchers have discovered that sexual minority youth often lack the support structures that most heterosexual teens use (Gonsiorek, 1998). Compared to LGBT adults, LGBT adolescents tend to have inadequate psychological, social, and economic resources (Cato, \& Canetto, 2003; McDaniel, et al., 2001; Rotheram- 
Borus, \& Fernandez, 1995). There is room for improvement in the ways schools, local health officials, families, peers, and community and religious organizations treat, view, and interact with sexual minority adolescents. There seems to be a systematic exclusion of and lack of support for LGBT youth from a variety of sources, including:

- Schools (Daria, \& Campbell, 2004; Macgillivray, 2000; Mufioz-Plaza, et al., 2002)

- Parents (D'Augelli, et al., 2005; Saltzburg, 2004)

- Communities and youth-serving organizations (D'Augelli, \& Hershberger, 1993; Nesmith, et al., 1999; Schneider, \& Owens, 2000)

Furthermore, research shows youth prefer to attend settings that are youth-oriented, but sometimes community centers that serve youth do not provide a welcoming environment for sexual minority youth (Stanley, 2003; Villarruel, et al., 2003). Many researchers agree that outlets for social support and creating opportunities for connection are critical for LGBT individuals (Hershberger, \& D'Augelli, 1995; Hollander, 2000; Oswald, 2000; Nesmith, et al., 1999; Savin-Williams, 1995; Robinson, 1994; Morrow, 1993).

For years, researchers have suggested that LGBT issues be included in youth development programming within community settings (Gerstel, et al., 1989; Singerline, 1994). Currently, national organizations have statements supporting this population such as the American Academy of Child and Adolescent Psychiatry, American Psychological Association, American School Counselor Association, National Association of School Psychologists, National Education Association, and the National Mental Health Association (APA, 2005).

\section{Processes for Institutional Support of LGBT Adolescents}

Research must examine the environment and culture within youth-serving organizations in regard to organizational support for LGBT youth. This will provide youth development professionals with a framework of contextual factors to begin integrating into organizations in order to build supportive processes that help these youth feel welcome and of value, rather than excluded and not of value (Barnett, \& Brennan, 2007; Barnett, \& Brennan, 2006). Volunteerism depends on youth involvement, therefore, motivations and barriers of LGBT adolescents are important to identify. The lack of research and conclusive evidence related to organizational support for LGBT youth led to the research question "What kinds of structures or processes are likely to enhance institutional change to support LGBT adolescents?"

\section{Youth Involvement}

The structures and processes of youth-serving organizations allow the five C's of youth development; competence, confidence, connections, character, and caring, to be put into practice. Roth and Brooks-Gunn (2003) concluded that the organizational environment must provide youth with support and empowerment through civic engagement or youth governance. Civic engagement includes giving youth a voice and allowing them to be agents of their own development by exhibiting confidence and competence (Camino, 2002). Competence grows when youth can help plan activities and programs. Youth should have a voice in defining goals for the programs in which they are involved. At an individual level, the inclusion of youth voices or governance allows youth to experience respect, be accepted by adults, and creates a positive channel for identity development and exploration (Yates, \& Youniss, 1999; Zeldin, 2004). This is especially significant for at risk or invisible youth, such as LGBT youth, who are unseen or ignored by a variety of societal institutions (Diversi, \& Mecham, 2005; Zeldin, et al., 2005). At a 
program level, youth voice in group decision-making is crucial because it ensures programs are focused on and include a diverse range of interests, experiences, and concerns of all adolescents (Denner, et al., 2005; Libby, et al., 2005; Zeldin, et al., 2005). Approximately 10\% of the population in a youth-serving organization is LGBT, but this number does not include their supportive friends who may also be involved in the organization. A logical extension of this argument is that there is a greater probability the LGBT population would be represented and given a voice if youth were allowed to participate in the governance and decision-making processes of the organization. This is just one potential way to produce organizational change within youth-serving organizations to better support LGBT youth.

\section{Diversity Training}

Diversity training programs increased dramatically in the late 1980's and early 1990's. This trend is likely to continue due to several factors, including changing workforce demographics, increasing globalization, and continuing conflict and litigation within organizational environments in regards to diversity (Bendick, et al., 2001; Buckel, 2000). Diversity trainings primarily have three objectives:

1) to increase knowledge and awareness about diversity issues;

2) to reduce biases and stereotypes; and

3) to change behaviors of individuals (Cox, 1993; Hanover, \& Cellar,1998; Roberson, et al., 2001; Sanchez, \& Medkick, 2004).

For example, the Safe Zone Project, a predominantly university-based diversity-training program, was designed to increase awareness and knowledge of, and sensitivity to, important issues affecting LGBT students, faculty and staff. The results of this project helped create a more open, supportive environment for LGBT individuals and increase the visibility of LGBT people and issues on a college campus (Evans, 2002; Finkel, et al., 2003). Also, faculty and staff hung "Safe Zone" cards on their walls and doors, as well as all over the entire department and training areas (Finkel, et al., 2003). Diversity awareness training about LGBT issues may not only increase people's knowledge, but also provide the stimulus for organizational behavioral change to better support sexual minority adolescents.

A step towards opening up a group or organization to include diverse members, such as sexual minority adolescents, includes creating settings where trainers who are LGBT are able to share their experiences (Bond, 1999; Reinharz, 1994). In the past, researchers have advocated using mixed race trainee groups for racial diversity training. This approach has been shown to increase the educational benefits of the training, as such approaches have produced beneficial results (Kirkland, \& Regan, 1997). Several researchers have found positive changes in racial attitudes as the result of racial diversity trainings (Cox, 1991; Hanover, \& Cellar, 1998; Sanchez, \& Mendick, 2004).

\section{Method}

\section{Participants}

In this study, a youth-serving organization is defined as an organization that primarily serves youth and that has year-round programs or services that focus on youth development. A youth or adolescent is defined as an individual ages seven to eighteen (Arnett, 2003). The Office of Community Service on the University of Florida campus provided a comprehensive list of 
community organizations in the Alachua County, Florida area. This list was cross-referenced with local and national websites and other local resources, including The Gainesville Chamber of Commerce and The United Way of North Central Florida's organization resource book. The total number of organizations on the list was 220.

The research utilized a two-phase design, a cross-sectional design in phase one and a theory building case study design in phase two. In phase one, a questionnaire was mailed to executive directors and religious leaders of the youth-serving organizations in Alachua County, FL. Fortysix total questionnaires out of 220 were received in the first round of data collection. It took three weeks to complete this process, yielding a $20.9 \%$ initial response rate.

In phase two, a self-completion questionnaire and a structured oral interview was administered with 18 individuals within six youth-serving organizations. Interviews were performed with an executive director or religious leader, a board member, and a youth program worker within each of the 6 organizations in the study. Seventeen interviews were performed at participants' offices and one was off-site at a nearby coffee shop. The response rate for the embedded units (18 participants) within the six organizations was $100 \%$.

\section{Sampling}

In phase one, a census was taken of the 220 youth-serving organizations to determine the level of youth involvement in decision-making within these organizations. Level of youth involvement in decision-making was used to select the organizations for phase two because there was no way to know a priori which organizations were supportive or not supportive of LGBT adolescents. Therefore, the general level of youth involvement was used instead.

In phase two, a maximum variation sampling approach was used. This sampling approach aims at capturing and describing the central themes or principal outcomes that cut across many participant or program variations (Patton, 1987). This approach is commonly used when a researcher believes that large differences between cases will provide the best opportunity for understanding the phenomena under study and it allows researchers to identify extremes in the outcome variable(s). It is also valuable when past research suggests there may be many factors involved in explaining a behavior. For purposes of this study, organizations at the two extremes, very supportive and unsupportive, would be most useful in determining the factors that contribute to organizational support for LGBT adolescents. In order to select organizations or cases for phase two, a summative score was created for the level of youth involvement for decision-making within all of the youth-serving organizations that responded to phase one of the research $(n=44)$. Organizations were divided into high and low levels of youth involvement in decision-making and three organizations were chosen with the highest and lowest scores.

\section{Instruments \& Structured Interviews}

An expert panel was used to create the indices used in the study. The questionnaire and structured interview were developed using experts such as University of Florida professors and researchers in the fields of psychology, community development, youth development, research design and methods, as well as community board members, youth workers, and executive directors from local nonprofit organizations, and two local religious leaders. The instrument was pre-tested with six members of the local community who were not included in the sample for phase two. Essential procedural steps were taken to ensure that the interview instruments were valid measurements of the main conceptual constructs and that they provided accurate 
information. The university institutional review board reviewed and approved all procedures. Informed consent sheets were signed by all participants prior to starting the interviews.

A) Organizational support (outcome variable): A two-dimensional index was used to measure the outcome variable, organizational support for LGBT adolescents. Participants responded on a 5 -point scale ( $1=$ always and $5=$ never). The statements were as follows:

1) Provide resource materials that are supportive of LGBT adolescents

2) Provide supportive counseling for LGBT adolescents when necessary.

3) Train volunteers and staff on issues facing LGBT adolescents and adolescents from same-sex families.

4) Recognize different types of family structures during group activities.

5) Take corrective, positive actions when an anti-gay remark has been made by an adult.

6) Take corrective, positive actions when an anti-gay remark has been made by an adolescent.

Open-response questions were also used to measure this variable. The questions are as follows:

30) A group of adolescents are engaged in a group activity. Suddenly, one adolescent yells to another, 'hey faggot, what are you doing?' The recipient of that remark starts to cry. What would your organization want you to do in this situation, or what is the policy of your organization in dealing with this type of situation?

31) A parent voices negative concern about an activity that dealt with lesbian, gay, bisexual, and transgender information. The parent has threatened to remove their child from your organization if the activity is stopped. What would your organization do in this situation, or, what is the policy of your organization in dealing with this type of situation?

32) If any, what kinds of experiences have you had in your job dealing with LGBT adolescents or issues?

33) Do you have any suggestions about how organizations should handle LGBT adolescents or issues?

B) Level of Youth Involvement (Independent variable): The questions used to measure this variable are as follows:

1) Do you have a Board of Directors? (Yes/No)

2) Do youth serve on your Board? (Yes/No)

3) If not, why not?

4) If yes, how many youth serve on the Board? (\# of youth)

5) Do youth serve on Board committees such as the hiring committee? (Yes/No)

6) Are you involved in the decision-making processes of program content, services, or activities? (Yes/No)

7) On a scale of 1-7 (where $1=$ not very often and $7=$ very often), with what frequency are youth involved in the decision-making?

8) Do youth have voting rights in the organization? (Yes/No) 
9) Are youth involved in determining goals for the organization? (Yes/No)

10) What is the percentage of organizational services or activities that are determined by youth? (percentage)

11) Are youth involved in the public relations aspect of the organization? (Yes/No)

12) Are youth involved in educating the community about issues? (Yes/No)

13) Do youth give feedback to organizational leaders about the programs and policies about the organization? (Yes/No)

14) What is the number of youth-led activities or programs? (Ranges $=0,1-3,4-6,7-9$, $10-12,13-16,17-19,20+)$.

Open-response questions about the level of youth involvement were asked in the second phase of the study. The questions are as follows:

1) Should adolescents be involved in the decision-making processes of the programs and activities of your organization? (Yes/No)

2) Why or why not?

3) Should adolescents have a forum to give feedback about the programs and activities they are involved in? (Yes/No)

4) Why or why not?

Diversity Training (Independent Variable): Participants were read the following definition about diversity training: "Training that addresses issues of race, gender, ethnicity, sexual orientation, age, and other differences." Participants were asked how many trainings of this type they had participated in during the past two years. If the answer was zero, they reported when and if the last time this training occurred. Participants stated the three major themes or ideas that were addressed in the most recent training, workshop, or continuing education program. The next set of questions dealt with three different types of diversity. First, participants were asked "how much of this most recent training dealt with gender diversity issues." They answered on a 5point scale ( $1=$ none and $5=$ =all). Importance was measured by asking "how important do you think it is to include gender diversity in these types of trainings?" ( $1=$ not very important and $5=$ very important). Finally, participants were asked "why or why not do you think it is important to include gender in these types of diversity trainings?" The same series of questions were asked about race and sexual orientation.

\section{Analysis}

Interviews were recorded and transcribed. Proper steps were taken to ensure consistency and reliability of the recorded data. The $n$ in the study was small $(n=18)$. This small sample size limited the statistical analysis that could be used to evaluate the differences between groups.

The statistical analysis for this study was performed using the software program Statistica, version 7.0. Three Mann-Whitney $U$ tests were used to determine if the 44 organizations who responded from the initial census in phase one were significantly different in terms of level of youth involvement, low, medium, and high. Next, a Kruskal-Wallis Test was used to determine if the medians differed among the three groups. A Mann-Whitney $U$ test was also used to determine if the six organizations in phase two were significantly different in terms of organizational support for LGBT adolescents. Emerging themes from the open-response questions were recorded. Finally, using a case-matching approach, tables were created to gain look at all of the cases and compare data across cases (de Vaus, 2001). 


\section{Results}

Our study revealed there are differences among youth-serving organizations with respect to levels of youth involvement.

Although youth are involved to a degree in all organizations, this study explored whether there were differences among high, medium and low levels of youth involvement. The Kruskal-Wallis Test revealed that there were statistical differences among the three levels of youth involvement ( $p$-value $<0.001$ ). Table 1 indicates that among the three groups, there are statistically significant differences of youth involvement.

Table 1

Kruskal-Wallis test for median differences among high, medium, low levels of youth involvement, Alachua County, Florida, 2006.

\begin{tabular}{|l|l|}
\hline & Score on Youth Involvement Variable $^{\mathrm{a}}$ \\
\hline Chi-Square & 33.290 \\
\hline df & 2 \\
\hline Asymp. Sig. & $<.001^{\mathrm{b}}$ \\
\hline
\end{tabular}

a. Grouping Variable: Level of Youth Involvement

b. Compared to $p$-value $<.05$

Three Mann-Whitney $U$ tests were used to examine whether there were between-group differences in terms of level of youth involvement among the initial 44 organizations which were categorized by high, medium, and low levels of youth involvement. The results of the comparison between organizations with low and medium levels of youth involvement are shown in Table 2.

Table 2

Mann-Whitney U 2-sample tests to compare organizations with low, medium, and high levels of youth involvement, Alachua County, Florida, 2006.

\begin{tabular}{|l|l|}
\hline $\begin{array}{l}\text { Group Comparisons for Level of Youth } \\
\text { Involvement Variable }\end{array}$ & P-values $^{\mathrm{a}, \mathrm{b}}$ \\
\hline Low-Medium & $<.001$ \\
\hline Medium-High & $<.001$ \\
\hline Low-High & $<.001$ \\
\hline
\end{tabular}

a. Grouping variable: Level of youth involvement

b. Compared to $\mathrm{p}$-value $<.05$

The Mann-Whitney $\mathrm{U}$ test was next used to examine whether within the six organizations with high levels and lowest levels of youth involvement, a relationship would be found between level of youth involvement and organizational support for LGBT adolescents (see Table 3). These two most extreme case study groups were not found to significantly differ in terms of organizational support for LGBT adolescents. Although differences were found among the six organizations, 
they were not significantly correlated with the outcome variable (level of organizational support for LGBT adolescents) (see Table 3).

\section{Table 3}

Mann Whitney U 2-sample test (normal approximation) to compare organizations with high $(n=3)$ and low levels of youth involvement $(n=3)$ with the outcome variable of organizational support for LGBT adolescents, Alachua County, Florida, 2006

\begin{tabular}{|l|l|}
\hline & Organizational Support Variable \\
\hline Mann-Whitney U & 3.00 \\
\hline $\mathbf{Z}$ & -.655 \\
\hline Asymp. Sig. (2-tailed) & .513 \\
\hline Exact Sig. [2(1-tailed Sig.)] & $.700^{\mathrm{a}, \mathrm{b}}$ \\
\hline
\end{tabular}

a. Grouping Variable: Level of Youth Involvement

b. Compared to $\mathrm{p}$-value $<.05$

The responses to the open-response questions provided a better picture of the organizational culture with regard to sexual minority adolescents within these youth-serving organizations. Responses to open-response indicate that the most supportive organizations $(E, D$, and $B$, respectively) gave similar responses about why the organization is supportive of LGBT adolescents. Responses included statements such as: "we promote diversity and handle all adolescents with respect," "our organization does not advocate for certain lifestyles, but would not discriminate either," and "we should teach tolerance and understanding about those who are different than we are."

The least supportive organizations ( $C, A$, and $F$, respectively) also had similar reasons for not supporting LGBT adolescents. These organizations gave responses such as "we do not discriminate, but no gays are allowed," "we would correct the statement, but we do not condone homosexuality," and "we should find the cause of homosexual feelings and show them what the Bible says about this immoral lifestyle." These responses raise the issue of how a youth-serving organization can promote leadership and character-building skills, while simultaneously discriminating against a segment of the population.

However, participants from all organizations in the study indicated that "this topic is relevant to today and there is more awareness about it now than there has been." They also said that "adolescents should not make derogatory remarks," "more and more adolescents have friends who are LGBT" and "people should not discriminate." The organizations differed in their definitions of support for these adolescents. The religiously-oriented organizations believe they are being supportive of LGBT adolescents because they are willing to counsel and listen to an adolescent in crisis. However, the conclusive message for LGBT adolescents is that being LGBT is not healthy. This failure to support LGBT adolescents has also resulted from political or religious pressures in many child welfare agencies (Mallon, 1992). This seems to be the case within the youth-serving organizations that scored low on the supportive action index in this 
study. In summary, it seems that some religious ideas or beliefs may negatively affect the environment in youth-serving organizations in regard to support for LGBT adolescents.

Analysis of the data for open-response questions listed in the methodology section indicate that there is a discrepancy between what people want in diversity training about LGBT issues and what they actually receive. For example, more than half of the participants felt this type of training was either "very important" or "somewhat important" (Refer to Table 4).

\section{Table 4}

How much of the content of the most recent diversity training for participants dealt with LGBT issues $(n=18)$, Alachua County, Florida, 2006

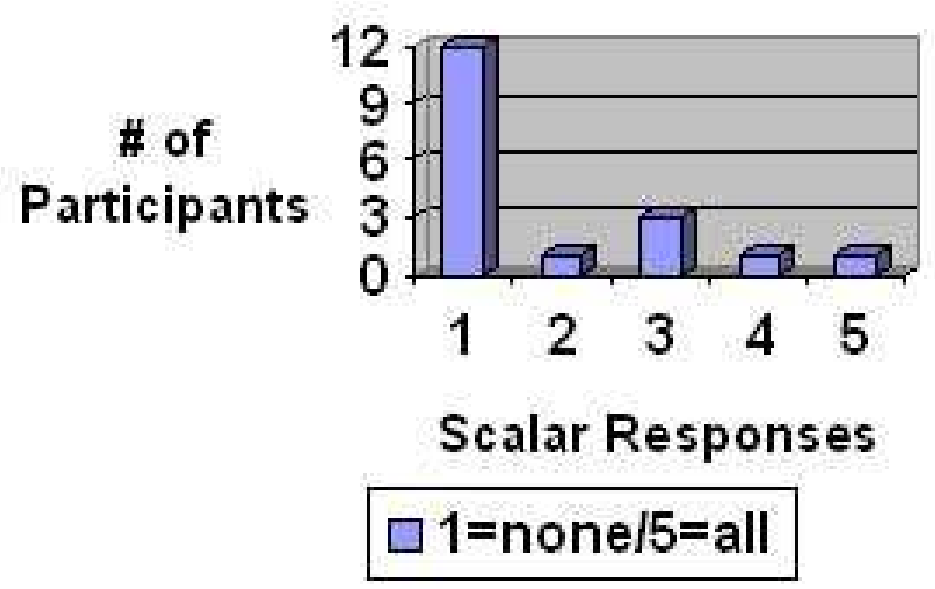

Yet, the majority of participants responded that none of the content in their most recent diversity training dealt with issues about sexual orientation (Refer to Table 5).

Table 5

How important participants felt the issue of sexual orientation was in diversity trainings $(n=18)$, Alachua County, Florida, 2006

\section{\# of Participants}

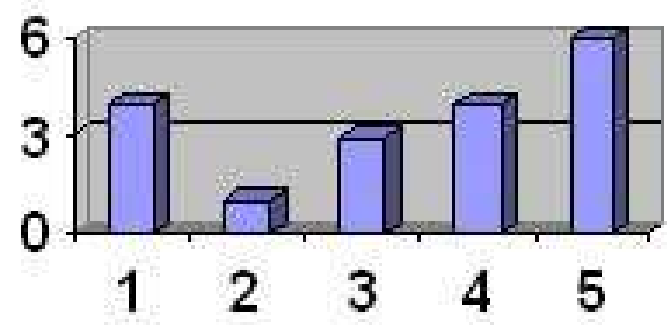

Scalar Responses 
Finally, only four participants received specific training about LGBT issues in their current job. All four of these participants come from an organization that is less supportive of LGBT adolescents ( $C$ and $A$, respectively) and the content of the training was that being LGBT is not acceptable.

\section{Implications for Research and Youth Practitioners}

Community-based youth-serving organizations can have a tremendous, positive impact on the development of our nation's children. These organizations have the potential to provide opportunities for youth to acquire personal and social assets, and experience features of positive developmental settings, such as teamwork, diversity, citizenship, leadership, character development, and well-being (Benson, 1997). They also have an opportunity to reach sexual minority or lesbian, gay, bisexual, and transgender (LGBT) adolescents. Rather than neglect and/or stigmatize these adolescents, organizations can model openness and teach both adolescent peers and mentors how to respect and appreciate differences as well as similarities.

The results of this study indicate that there are several steps organizations and practitioners can take to be more supportive of LGBT adolescents. First, organizations could allow youth to be more involved in the decision-making and programming. Secondly, organizations could provide supportive diversity training about LGBT issues for board members, staff, and age-appropriate training for adolescents

\section{Youth Involvement}

Research shows that many community-based organizations do not involve youth in decisionmaking and interaction with adults, even though research shows this promotes youth and organizational development (Camino, 2002; Flanagan, \& Faison, 2000; Zeldin, 2004). Youth involvement can be challenging and perhaps threatening to some organizations.

Implementation usually requires a shift in traditional roles among adults and youth and significant policy and programmatic changes within youth-serving organizations (Camino, \& Zeldin, 2002; Larson, et al., 2005). The results of this study suggest that the level of youth involvement was not necessarily correlated with the outcome variable organizational support for LGBT adolescents, but further research is necessary to test the assumption that this variable may be causally linked to the outcome measure. More precise measurements of level of youth involvement should be used to determine if this variable is causally linked to organizational support for LGBT adolescents. Research must further examine youth involvement within more youth-serving organizations for comparison.

Results of this study also appear to support past research that found youth engagement in service to others and their community can play an important role in the healthy development of young people (Rodine, et al., 2006). Furthermore, these preliminary findings support the notion that youth involvement is growing among youth-serving organizations. More precise measures of this concept should be used for future studies. Also, future studies could obtain the insight of adolescents themselves, as research shows this age group tends to be more welcoming and supportive of LGBT individuals (Herek, 2002; SIECUS, 2001).

Finally, there is a lack of research about successful adolescent development and same-sex attraction, as well as the strengths and assets of the LGBT adolescent population (Busseri, et al, 
2006). There may be answers in that research that could be applied to an organizational setting, such as how gender roles among LGBT adolescents may differ from heterosexual adolescents, and the implications of these differences for youth programmatic leaders to consider when working with a large group that includes both populations. It is critical that youth leaders understand the social and emotional identity clarifications adolescents in both groups are seeking through gender role and sexual identity development. Organizations may experience some transitional phases of acceptance and involvement between group members as increasing numbers of adolescents choose to be more open with their sexual orientation.

\section{Diversity Training}

Organizations could provide supportive diversity training about LGBT issues for board members, staff, and age-appropriate training for adolescents. The majority of participants in the study indicated they and other individuals in their organization need more training in this area. Individuals from supportive and less supportive organizations both said they need more training, regardless of whether or not the organization as a whole was supportive of LGBT adolescents. Organizations could also train parents and work with local opinion leaders. Building community-wide coalitions and networks is crucial for any real change to occur.

Future studies dealing with the concept of sexual orientation should include strategies to desensitize the issue. In this study, questions were asked about general diversity, gender diversity, and racial diversity before questions about sexual orientation. This approach seemed to be effective in eliciting more straightforward information about such a sensitive topic. Furthermore, because the questions about sexual orientation came towards the middle of the interview, participants were given time to feel comfortable and open to talking about diversityrelated issues.

\section{Conclusion}

It is important to reexamine the level of youth involvement in decision-making and the amount of supportive diversity training about LGBT issues offered within youth-serving organizations. Organizations think these two concepts are important, but not necessarily in regard to LGBT adolescents. It is inconsistent to have a focus on positive youth development, but to exclude sexual minority adolescents. If attention is drawn to these discrepancies, perhaps more organizations will take notice and make changes. All adolescents must be allowed to explore their identities in a safe, welcoming environment. Exploring their identities through involvement in decision-making is of vital importance to the well-being of youth and the success of youth development programming. The rigorous work on the topic of sexual orientation, both in the area of research and in our communities, must continue if we are going to achieve the goal of creating safe and supportive environments for all adolescents. 


\section{References}

American Psychiatric Association (APA). (2005). Gay and Lesbian Issues. Retrieved April 10, 2005 from http://www.psych.org/public info/homose 1.cfm.

American Academy of Pediatrics (AAP). (2002). Coparent or Second-Parent Adoption by SameSex Parents. Committee on Psychosocial Aspects of Child and Family Health Pediatrics 109: 339340.

Arnett, J.J. (2003). Adolescence and emerging adulthood: A cultural approach. Upper Saddle River, New Jersey: Prentice-Hall, Inc.

Badgett, M., Lee, M., \& Rogers, M. (2003). "Left Out of the Count: Missing Same-Sex Couples in Census 2000." Amherst, MA: Institute for Gay and Lesbian Strategic Studies (IGLSS).

Barnett, R.V., \& Brennan, M.A. (2006). Integrating youth into community development: Implications for policy planning and program evaluation. Lead feature article, June 2006: Journal of Youth Development: Bridging Research to Practice. 16 pages.

Barnett, R.V., \& Brennan, M.A. (2007). Youth Volunteers: The Effects of Influences, Motivations and Receptivity on Volunteerism. (In review: International Journal of Volunteer Administration.)

Bendick, M., Egan, M.L., \& Lofhjelm, S.M. (2001). Workforce diversity training: From antidiscrimination compliance to organizational development. Human Resource Planning, 24(2), 1026.

Benson, P.L. (1997). Al/ Kids Are Our Kids. San Francisco: Jossey-Bass.

Bond, M.A. (1999). Gender, race, and class in organizational contexts. American Journal of Community Psychology, 27(3), 327-354.

Buckel, D.S. (2000). Legal perspective on ensuring a safe and nondiscriminatory school environment for lesbian, gay, bisexual, and transgendered students. Education and Urban Society, 32(3), 390-398.

Busseri, M.A., Willoughby, T., Chalmers, H., \& Bogaert, A.R. (2006). Same-sex attraction and successful adolescent development. Journal of Youth and Adolescence, 35(4), 563-575.

Camino, L. (2002). From periphery to center: Pathways for youth civic engagement in the day to day life of communities. Applied Developmental Science, 6, 213-220.

Casper, V., \& Schultz, S. B. (1999). Gay parents/straight schools: Building communication and trust. New York, NY: Teachers College Press.

Cass, V.C. (1979). Homosexual identity formation: A theoretical model. Journal of Homosexuality, 4, 219-235. 
Cass, V.C. (1996). Sexual orientation identity formation: A western phenomenon. In R.P. Cabaj, \& T.S. Stein (Eds.), Textbook of homosexuality and mental health (pp.227-251). Washington, D.C.: American Psychiatric Press.

Cato, J., \& Canetto, S.S. (2003). Young adults' reactions to gay and lesbian peers who became suicidal following "coming out" to their parents. Suicide and Life-Threatening Behavior, 33(2), 201-210.

Cobb, N.J. (2004). Adolescence: Continuity, change, and diversity. (5 $5^{\text {th }}$ Ed.). New York, NY: McGraw-Hill Companies, Inc.

Cochran, S., \& Mays, V. (2001). Mental Health Correlates of Perceived Discrimination Among Lesbian, Gay, and Bisexual Adults in the United States. American Journal of Public Health, 91(11),1869-1876.

Cox, T. (1993). Cultural diversity in organizations: Theory, research and practice. San Francisco, CA: Berret-Koehler.

Cox, T. (1991). The multicultural organization. Academy of Management Executives, 3, 34-47.

D'Augelli, A.R. (1996). Enhancing the development of lesbian, gay, and bisexual youths. In E.D. Rothblum, \& L. Bond (Eds.), Prevention of heterosexism and homophobia (pp. 124 -150). Newbury Park, CA: Sage Publications.

D'Augelli, A.R., Grossman, A.H., \& Starks, M.T. (2005). Parents' awareness of lesbian, gay, and bisexual youths' sexual orientation. Journal of Marriage and Family, 67, 474-482.

D’Augelli, A.R., \& Hershberger, S. (1993). Lesbian, gay, and bisexual youth in community Settings: Personal challenges and mental health problems. American Journal of Community Psychology, 21, 421-448.

D'Augelli, A.R., Hershberger, S., \& Pilkington, N. (2002). Incidence and mental health impact of sexual orientation victimization of lesbian, gay and bisexual youths in high school. School Psychology Quarterly, 17(2), 148-167.

D'Augelli, A.R., Hershberger, S., \& Pilkington, N. (2001). Suicidality patterns and sexual orientation-related factors among lesbian, gay and bisexual youths. Suicide and LifeThreatening Behavior, 31(3), 250-264.

Daria, M., \& Campbell, K. (2004). Schools need sexuality education programs. Electronic Journal of Human Sexuality, 7, 1-3.

Denner, J., Meyer, B., \& Bean, S. (2005). Young women's leadership alliance: Youth-adult partnerships in an all-female after-school program. Journal of Community Psychology, 33(1), 87-100.

de Vaus, D. (2001). Research Design in Social Research. Thousand Oaks, CA: Sage Publications. 
Diversi, M., \& Mecham, C. (2005). Latino(a) students and Caucasian mentors in a rural afterschool program: Towards empowering adult-youth relationships. Journal of Community Psychology, 33(1), 31-40.

Evans, N.J. (2002). The impact of an LGBT Safe Zone project on campus climate. Journal of College Student Development, 43, 522-539.

Finkel, M.J., Storaasli, R.D., Bandele, A., \& Schaefer, V. (2003). Diversity training in graduate school: An exploratory evaluation of the Safe Zone Project. Professional Psychology: Research and Practice, 34(5), 555-561.

Flanagan, C., \& Faison, N. (2000). Youth civic development: Implications for social policy and programs. Social Policy Report Series. Ann Arbor, MI: Society for Research in Child Development.

Garofalo, R., Wolf, R.C., Wissow, L.S., Woods, E.R., \& Goodman, E. (1999). Archives of Pediatric Adolescent Medicine, 153(5), 487-93.

Garofalo, R., Wolf, C., Kessel, S., Palfrey, J., \& DuRant. R. (1998). The association between health risk behaviors and sexual orientation among a school-based sample of adolescents, Pediatrics, 101, 895-902.

Gates, G., \& Ost, J. (2004). The Gay and Lesbian Atlas. Washington, D.C.: Urban Institute Press.

Gerstel, C.J., Feraios, A.J., \& Herdt, G. (1989). Widening circles: An ethnographic profile of a youth group. Journal of Homosexuality, 17, 75-92.

Gonsiorek, J. (1998). Mental health issues of gay and lesbian adolescents. Journal of Adolescent Health Care, 9, 114-122.

Grossman, A.H., \& Kerner, M.S. (1998). Support networks of gay male and lesbian youth. Journal of Gay, Lesbian, and Bisexual Identity, 3(1), 27-46.

Hanover, J.M.B., \& Cellar, D.F. (1998). Environmental factors and the effectiveness of workforce diversity training. Human Resource Development Quarterly, 9(2), 105-125.

Herdt, G., \& Boxer, A. (1993). Children of horizons: How gay and lesbian teens are leading a new way out of the closet. Boston, MA: Beacon Press.

Herek, G.M. (2002). Heterosexuals' attitudes toward bisexual men and women in the United States. Journal of Sex Research, 39(4), 264-274

Herek, G.M. (1988). Heterosexuals' attitudes toward lesbians and gay men: Correlates and gender differences. Journal of Sex Research, 25, 451-477.

Hershberger, S.L., \& D'Augelli, A.R. (1995). The impact of victimization on the mental health and suicidality of lesbian, gay and bisexual youths. Developmental Psychology, 31(1), 65-74. 
Hetrick, E., \& Martin, D. (1987). Developmental issues and the irresolution for gay and lesbian adolescents. Journal of Homosexuality, 14, 13-24.

Hollander, G. (2000). Questioning youths: Challenges to working with youths forming identities. School Psychology Review, 29(2), 173-179.

Human Rights Watch (HRW). (2001). Hatred in the hallways. Retrieved July 6, 2006 from http://www.hrw.org/reports/2001/uslgbt/.

Human Rights Watch (HRW). (2005). Gay and Lesbian Families in the United States: Same-sex unmarried partner households. A Preliminary Analysis of 2000 United States Census Data. A Human Rights Campaign Report. Retrieved June 1, 2005 from http://www.hrc.org/Content/ContentGroups/Publications1/census.pdf.

Kirkland, S.E., \& Regan, A.M. (1997). Organizational racial diversity training. In Thompson C.E., \& Carter, R.T. (Eds.). Racial identity theory: Applications to individual, group, and organizational interventions (pp.159-175). Mahwah, NJ: Erlbaum.

Kruks, G. (1991). Gay and lesbian homeless/street youth: special issues and concerns. Journal of Adolescent Health, 12(7), 515-518.

Larson, R., Walker, K., \& Pearce, N. (2005). A comparison of youth-driven and adult-driven programs: Balancing inputs from youth and adults. Journal of Community Psychology, 33(1), 57-74.

Lassiter, P., Dew, B., Newton, K., Hays, D., \& Yarbrough, B. (2006). Self-defined empowerment for gay and lesbian parents: A qualitative examination. The Family Journal, 14(3), 245-252.

Libby, M., Rosen, M., \& Sedonaen, M. (2005). Building youth-adult partnerships for community change: Lessons from the Youth Leadership Institute. Journal of Community Psychology, 33(1), 111-120.

Macgillivray, I.K. (2000). Educational equity for gay, lesbian, bisexual, transgendered and queer/questioning students: The demand for democracy and social justice for America's schools. Education and Urban Society, 32(3), 303-323.

Mallon, G. (1992). Gay and no place to go: Assessing the needs of gay and lesbian adolescents in out-of-home care settings. Child Welfare, 6, 547-556.

McDaniel, J.S., Purcell, D., \& D'Augelli, A.R. (2001). The relationship between sexual orientation and risk for suicide: Research findings and future directions for research and prevention. Suicide and Life-Threatening Behavior, 31, 84-105.

Morrow, D.F. (1993). Social work with gay and lesbian adolescents. Social Work, 38, 655-660. 
Mufioz-Plaza, C., Quinn, S.C., \& Rounds, K.A. (2002). Lesbian, gay, bisexual and transgender students: Perceived social support in the high school environment. The High School Journal, 1 , 52-63.

National Mental Health Association (NMHA). (2005). What does gay mean? Retrieved on July 3, 2006 from http://www.nmha.org/whatdoesgaymean/whatDoesGayMean/pdf.

National Runway Switchboard (NRS). (2006). NRS call statistics: 2005. Retrieved June 1, 2006 from http://www.nrscrisisline.org/news events/call stats.html.

Nesmith, A.A., Burton, D.L., \& Cosgrove, T.S. (1999). Gay, lesbian, and bisexual youth and young adults: Social support in their own words. Journal of Homosexuality, 3ᄌ1), 95-109.

Oswald, R.F. (2000). Family and friendship relationships after young women come out as bisexual or lesbian. Journal of Homosexuality, 38(3), 65-83.

Patterson, C.J. (1995b). Lesbian mothers, gay fathers and their children. In A.R. D'Augelli, \& C.J. Patterson (Eds.), Lesbian, gay and bisexual identities over the lifespan. New York, NY: Oxford University Press.

Patton, M.Q. (1987). How to use qualitative methods in evaluation. Newbury Park, CA: Sage Publications, Inc.

Reinharz, S. (1994). Toward an ethnography of "voice" and "silence." In E. Trickett, R. Watts, \& D. Birman (Eds.), Human diversity: Perspectives on people in context (pp.178-200). San Francisco, CA: Jossey-Bass.

Remafedi, G. (1987). Adolescent homosexuality: Psychosocial and medical implications. Pediatrics, 79, 331-337.

Rivers, I. (2000). Social exclusion, absenteeism and sexual minority youth. Support for Learning, 15(1), 13-18.

Roberson, L., Kulik, Carol T., \& Pepper, M.B. (2001). Designing effective diversity training: Influence of group composition and trainee experience. Journal of Organizational Behavior, 22(8), 871-885.

Robinson, K.E. (1994). Addressing the needs of gay and lesbian students: The school counselor's role. The School Counselor, 41, 327-333.

Rodine, S., Omen, R., Vesely, S., Aspy, C., Tolma, E., et al. (2006, May). Potential protective effect of the community involvement asset on adolescent risk behaviors. Journal of Youth Development: Bridging Research and Practice, 1(1), Article 601FA005. Retrieved August 3, 2006 from http://www.nae4ha.org/directory/jyd/jyd article.aspx?id=2ad1d22e-4f37-425d-aeba0b9919643f05.

Roth, J., \& Brooks-Gunn, J. (2003). Youth development programs: Risk, prevention and policy. Journal of Adolescent Health, 32(3), 170-82. 
Rotheram-Borus, M.J., \& Fernandez, M.I. (1995). Sexual orientation and developmental challenges experienced by gay and lesbian youths, Suicide and Life Threatening Behavior, 25, 26-34.

Russell, S., Seif, H., \& Truong, N. (2001). School outcomes of sexual minority youth in the United States: Evidence from a national study. Journal of Adolescence, 21(1), 111-127.

Saltzburg, S. (2004). Learning that an adolescent child is gay or lesbian: The parent experience. Social Work, 49(1), 109-118.

Sanchez, J.I., \& Medkick, N. (2004). The effect of diversity awareness on differential treatment. Group and Organizational Management, 29, 517-536.

Savin-Williams, R.C. (1995). Lesbian, gay male, and bisexual adolescents. In A.R.C.J. Patterson (Eds.), Lesbian, gay and bisexual identities over the life span: Psychological perspectives (pp. 165-189). New York, NY: Oxford University Press.

Schneider, M.E., \& Owens, R.E. (2000). Concern for lesbian, gay, and bisexual kids. Education and Urban Society, 32(3), 349-367.

SIECUS Report. (2001, April/May). Lesbian, gay, bisexual and transgender youth issues, 29(4). Retrieved October 1, 2005 from http://www.siecus.org/pubs/fact/fact0013.html

Simmons, T., \& O'Connell, M. (2003). "Married-Couple and Unmarried-Partner Households: 2000." Census 2000 Special Reports. Washington, D.C.: U.S. Census Bureau.

Singerline, H. (1994). Outright: Reflections on an out-of-school gay youth group. High School Journal, 77, 133-137.

Stanley, J.L. (2003). An applied collaborative training program for graduate students in community psychology: A case study of a community project working with lesbian, gay, bisexual, transgender, and questioning youth. American Journal of Community Psychology, 31(3/4), 253-266.

Tye, M. (2003). Lesbian, gay, bisexual, and transgender parents: Special considerations for the custody and adoption evaluator. Family Court Review, 41(1), 92-103.

Unks, G. (1993). Thinking about the homosexual adolescent. The High School Journal, 1, 1-6.

Villarruel, F.A., Perkins, D.F., Borden, Lynne, M., \& Keith, J.G. (2003). Community youth development: Programs, policies, \& practices. Thousand Oaks, CA: Sage Publications.

Williams, T., Connolly, J., Pepler, D., \& Craig, W. (2005). Peer victimization, social support, and psychosocial adjustment of sexual minority adolescents. Journal of Youth and Adolescence, $34(5), 471-482$. 
Yates, M., \& Youniss, J. (Eds.). (1999). Roots of civic identity: International perspectives on community service and youth activism. New York, NY:University Press.

Zeldin, S. (2004). Youth as agents of adult and community development: Mapping the processes and outcomes of youth engaged in organizational governance. Applied Developmental Science, 8(2), 75-90.

Zeldin, S., Larson, R., Camino, L., \& O'Connor, C. (2005). Intergenerational relationships and partnerships in community programs: Purpose, practice, and directions for research. Journal of Community Psychology, 33(1), 1-10.

(C) Copyright of Journal of Youth Development Bridging Research and Practice. Content may not be copied or emailed to multiple sites or posted to a listserv without copyright holder's express written permission. Contact Editor at: patricia.dawson@oregonstate.edu for details. However, users may print, download or email articles for individual use.

ISSN 2325-4009 (Print); ISSN 2325-4017 (Online) 